\title{
An Exploration of Adamu Kyuka \\ Usman's Style of Introduction in Hope in Anarchy
}

\section{Muniru Oladayo Murana}

\section{Hafsat AbdulWahab}

\begin{abstract}
Every good piece of writing, fictional or otherwise is marked by a good introduction. This initial part is the primary provider of the reader's first impression that sustains the reading. The introduction as well as the other parts of a written or spoken text is essentially realized through specially selected language. In prose fiction, special selections and patterns are the hallmarks. This paper explores the devices of style deployed by Usman in the creation of the introduction to Hope in Anarchy. It involves an intensive reading of the first chapter of the novel to unravel its artistic underpinnings for creating and sustaining the interest of the reader in the story. This thorough reading follows a general but careful reading of the entire text to establish the writer's preoccupation and general tone. Excerpts from the introductory chapter form the data, and the analytical framework is linguistic stylistics. The analysis reveals that the novelist annexes contrastive lexical and syntactic devices, adjectives and adverbs of varied types and semantic nuances and morpho-phonological choices to introduce and delineate characters, develop events and create suspense. The paper concludes that both the novelty and typicality of the narrative derive from these stylistic constructs.
\end{abstract}

\section{Keywords}

Stylistic Devices, Reader's Interest Sustenance, Introduction, Hope in Anarchy 


\title{
An Exploration of Adamu Kyuka Usman's Style of Introduction in Hope in Anarchy
}

\author{
Muniru Oladayo Murana \\ Hafsat AbdulWahab
}

\section{Introduction}

The task of introducing a fictional narrative is understandably complex. It is the creative resolution of the writer that, however, serves to surmount this arduous task. Every writer makes presuppositions about the textual message and the reader. This is because no writer arguably writes only to a while away time. The writing is also informed by certain preoccupations which serve to motivate and sustain it. These can be gleaned from the thrust of the work or its theme(s). The writer makes choice of one at a time out of the different story-production, propelling experiences and a network of triggering imaginations. The choice of what to write about, the content or storyline is arguably as important as the choice of how to write, the manner, or more specifically, how to start - the introduction. These are requisite for creating a worthwhile fiction.

Introduction in narratology, also called prolegomenon, is the act of beginning or initiating a narrative. It is the beginning which opens and projects the writing. It is embarked upon after the narrator has made the important choice of style to make the remaining parts of the narration feasible, promising and coherent. The success of a creative narration largely depends on the introduction which lays the foundation for smooth composition and sequencing. The introduction also reassures the writer of the desirability and naturalness of the unfolding story.

The reader, the writer's target, is directly affected by the introduction of a story. The impression created by it is important in deciding the desirability or otherwise of the fiction as well as the readiness to further expend valuable time on its reading. From the foregoing, introduction serves as a background for textual composition, acceptability and interpretation. Its style is, therefore, important as its content. This paper consequently examines the style of introduction in Adamu Kyuka Usman's Hope in Anarchy to reveal the artistic foundation responsible for its success.

\section{Style in Prose Literature}

Literature is a product of language and its hallmark seems to be the eternal freshness of its language. Moody (1968) notes that it springs from our inborn love of 
telling story, of arranging words in pleasing patterns, of expressing in words some special aspects of human experience'(2). Literature thrives on special selection of language and, as Lawal (1997) argues, the relationship between the two 'is dialectical due to their substantial overlap' (2). More specifically, prose narrative involves elaborate creative account of sequence of interrelated events running over pages. Its distinguishing features are especially measurable 'over a long stretch of texts, and to be demonstrable ultimately only in quantitative terms' (Leech and Short, 3). Some of these features are: apposite introduction that progressively moves towards the body of the story, apt syntax and appropriate diction (Olaofe and Kazim, 2013). Varied strategies are employed in the development of narrative and these strategies are directed towards stimulating interest, curiosity or suspense. Abubakar (1997) appositely explains the novelist's motivation for suspense creation:

But from the point of view of narrative development, a writer will wish to present information bit by bit in order to retain the reader's interest, and manipulate his relative lack of information in order to make him read on, so as to find out what is as yet not supplied(17).

Information about characters and events is given piecemeal from the introduction of a narrative and this stage also marks the beginning of suspense creation. Language is the facility employed in achieving this task. Language in this wise is used stylistically as to be literarily enchanting. Consequently, a 'literary expression is an enhancement or a creative liberation of the resources of language we use from day to day' (Leech and Short 6).

Creative liberation or novelty in all its ramifications constitutes style: the object of study in stylistics. The similitude of the interface between language and literature is the nexus between language and style - literature exists through the deft deployment of language just as 'language is the context in which style is cultivated' (Oyeleye 254). Stylistics is not only the science of literature though it gives 'special attention to the most conscious and complex uses of language in literature' (Turner 8). The world of literature is linguistically enabled; it is a world construed via the facility of language and its construction essentially involves choice making from the network of options available in the language of its being. Style is a product of choice. It results from a "tendency [...] to consistently choose certain structures over others available in the language' (Traugott and Pratt 29). The creative writer engages in choice making from among competing variants and the context is an inevitable ally in this task. Stylistics, thus, is an attempt to unveil "the artistic principles underlying a writer's choice of language' (Leech and Short 74).

This paper examines the first chapter of Usman's Hope in Anarchy to reveal the various stylistic options made in its composition and the motivations for such options. It is limited to the first chapter to achieve a fairly thorough analysis. The analysis leans heavily on the systemic functional linguistic perspective that perceives language as a 
resource for making meaning based on context.

\section{Hope in Anarchy: A synopsis}

The novel was published in 2005. It presents the story of a nation characterized by gross inequality between the few rich and the majority poor. The poor consequently live in abject poverty and lack against the abundance and superfluity of the affluent with the repercussion of mutual hatred between these two divides of the same society. The story is wound around Ahoka, the son of an ex-service man. The father, Solo, is ejected from his rented bed sitting room for his inability to pay. Ahoka and Solo consequently live under Asabeni Bridge. The father works as a night watchman for the rich Okime's family, while the son picks and sells discarded empty bottles and tins having been expelled from school in his fourth year for his father's failure to pay the compulsory book fee of seven thousand rida due to poverty. Jukolo, one of the poor forms a clandestine reactionary group, the exorcism and incorporates many others. The deadly cult attacks the rich at night and annihilates their families. Solo being among the pioneer members soon becomes a gallant knight in the Mermaid Shell, their secret abode. His popularity courts Jukolo's envy and the latter soon secretly exterminates him. Ahoka continues to live alone following his father's disappearance and he too soon finds himself in Jaruwa Prison due to the ploy of the policemen who dupe him of the money given as a reward for discovering Madam Narosi's lost chain. The exorcism soon becomes a big threat to the government as lives are unsafe and anarchy reigns everywhere. Unfortunately, the rules of exorcism are soon violated by the exorcists and the leader, Jukolo becomes autocratic and erratic. While in the prison, Ahoka discovers the source of his lost father's death and expectedly hopes for revenge. His opportunity finally comes as the exorcists become disunited. Jukolo is wounded from the ensuing conflict among the exorcists at the prison forecourt and Ahoka strikes. Exorcism fails and its attendant hope drains.

\section{A Stylistic Exploration of the Introduction of Hope in Anarchy}

The first chapter of the novel spans over the first six pages. In this chapter the complexly woven story is introduced through the introduction of the reader to Ahoka, the principal character around whom the narrative is wrought. Ahoka's life and living are presented as hopeless and hapless in spite of his agility and personableness through the author's choice of complex sentences, potentially transitive but objectless verbs and other suggestive stylistic options. The first three sentences of the chapter suffice for initial illustration:

Ahoka stretched, turned and gradually sat up under the bridge. He was a tall a fair complexioned boy always wearing a brooding expression on his face. Asabeni bridge located between Desowa and Beku Island had become his only home since the day he and 
his father were thrown out of their one-room apartment in Desowa because they could not pay the three thousand rida monthly rent demanded by his landlord. (1)

The premier sentence is multiple and through its triad of independent clauses. Ahoka's active nature is underlined. The series of physical actions, simultaneous or sequential, are predictive of a determined character unfolding. The author's choice of the active voice lends credence to this reading. However, the first two verbs, potentially transitive though, have their objects ellipsed. The reader is not told about the stretched and turned parts of his body. These are considered as presupposed. The author's deliberate construction of the two verbs as intransitive despite their active form is of stylistic relevance. Ahoka's activity is suggestively undermined by factors to be discovered in the unfolding narrative.

The second sentence increases the reader's knowledge of Ahoka through a series of attributive adjectives. While his height (tall) and complexion (fair) are attractive; his look (brooding) is pitiable. These contrastive features complement the author's construction of 'stretched' and 'turned' as intransitive. Again, Ahoka is more expressly introduced as a destitute through his residence introduced by the prepositional phrase functioning as adjunct: 'under the bridge' in the first sentence and the mood adjunct of usuality - 'always', introducing the second clause of the second sentence provides the author's comment on the degree of permanence of his sadness owing to his state of penury and homelessness. The high level of oftenness signified by this modality prepares the reader's mind for the tendency that Ahoka's destitution might be long lasting. This justifies the novelist's preference for always over other mood adjuncts of usuality such as: never, seldom, sometimes, etc.

The story progresses coherently with further exposition of Ahoka' abode in the third sentence. The bridge is presented as an isolate or a detachment through the preposition, 'between'. It is neither in Desowa nor in Beku Island. Yet Ahoka has no other domiciliary options other than this detached bridge. His acute restriction or choicelessness is the basis for the author's use of 'only' in '... his only home'. The limiter adjective 'only' (Quick and Greenbaum 122) particularizes its referents banning other similar references. The reader is propelled to anticipate by his or her knowledge of the real world that in spite of the various contradictions and restriction lexically and structurally coded by the writer, Ahoka's emancipation over time is still a possibility. This anticipatory hunch is apt in sustaining the reader's interest and more so at the introductory part of the narrative.

The next character introduced after Ahoka is his father. A hard circumstance such as Ahoka's warrants the question of the identity of his parents especially in the African context, his father. Appropriate lexical set collocate perfectly forming the author's stylistic tool for this purpose. These set include: 'a watchman', 'his faded jacket', 'the big pockets', 'his snoring habit', 'his nasal strains', 'this irritation', and 'his father's ability to sleep' (1). These nominal groups or noun phrases excerpted from sentences 
where they are either subjects, objects or complements are a graphic categorization device to reveal his profession (a watchman), financial status (faded jacket, big pocket), social cum health state (his snoring habit, his nasal strains, this irritation and his ability to sleep). Ahoka's father is the principal destitute whose solace is in his ability to sleep soundly in spite of all hindrances. His name, Solo, is not mentioned throughout the introduction because he is a socio-economic nonentity. Besides, the delay is a deviation, a stylistic device of foregrounding intended to create suspense and motivate further reading of the novel.

The consistently sad appearance of Ahoka is a sequel to his dissatisfaction with his condition though his father seems complacent. Their contrastive disposition is lexically and grammatically coded through adversative, mood adjunct and negative polarity as the next excerpts below show:

Though the bridge had been his home for year now he never seemed to get used to it. (p.2)

Though his father...often caught fish in the lagoon, particularly at night, this was not enough to make up for the horror of living under the bridge. (2)

Unlike Ahoka's father who sleeps and snores against all odds, Ahoka is not comfortable with his life under the bridge. Their age differences and life experiences count in accounting for this difference. The clause of contrast initiated by the contrastive adverbial, 'though', in the first excerpt acknowledges the length of the years already spent by Ahoka and his father under the isolated Asabeni Bridge while the main clause in the sentence presents the state of his familiarity with the place. More specifically, the adjunct, 'for years now', contrasts with the mood adjunct of usuality - 'never' to break the reader's expectation and presuppose the probability of Ahoka's seeking another option against his father's seeming complacency. Similarly, in the second excerpt, the initial contrastive adjunct, 'though', lexicalizing concession is contrasted and undermined by the negative polarity of the finite 'was' in 'was not enough'. Thus, the benefit of regular access to sea food, particularly 'fish' is nothing compared to the danger of constant exposure to fright semantically included in 'horror'. Fish and horror are consequently contextually antonymous. Both the lexical and structural contrasts are designed to present the attitudinal difference between the son and the father and heighten the reader's curiosity.

The corollary to the contrastive dispositions of Ahoka and his father is the tendency for the reader to think that Ahoka would abandon his father in the long run. To moderate this guess in the light of the later events in the story, the author makes transparent choices of roles and process types to unveil clearer character of Ahoka through his action, thought and feeling for his poor father. Choices of roles and process types are choices from the transitivity system (Halliday, 2004). These choices are analyzed next through the four excerpts below: 
...he threw a pitiful glance at his father sleeping on his back near him. (1)

Again Ahoka peeked at his father, then looked away into the nearby bush. (3)

... he wondered how his father could keep armed robbers at bay using such stick as his only weapon. (4)

But the fear for his father still haunted him. (5)

Ahoka is portrayed as a compassionate and loving child via the varied choices made for him in the texts above. In the first excerpt, out of respect and love, his look at his father is consistently a glimpse or peep. The choice of the role made for his depiction from the transitivity system in each of the initial clauses in the first two excerpts is actor. This is partly responsible for the semantic concord between them. The first clause: 'he (Ahoka) threw a pitiful glance at his father' is a paraphrase of the second - 'Ahoka peeked at his father'. The inaccessible working of Ahoka's mind is presented in the third excerpt. Through the mental process involved, Ahoka is a sensor. He is worried about his father's safety and the thought of how his father achieves safety without any weapon is the phenomenon he perceives. This second emotion-laden role is the precursor of this fear in the last excerpt where he is the goal and the fear for his father is the actor that torments him. These two processes - physical and mental and their associated roles of actor, sensor and goal serve to present a second dimension to Ahoka's nonconforming stance. It becomes clear that Ahoka may remain at least emotionally attached to his father throughout the story.

The second category of people presented in the introduction besides the destitute are the affluent. Though their voice is not yet heard, their action, behavior and the perspective of the poor about them are briefly hinted for further elaboration in subsequent chapters. The earlier cited third sentence of the introduction is reproduced below to initiate our exposition of the relevant stylistic facilities employed for presenting the rich:

Asabeni bridge located between Desowa and Beku Island had become his only home since the day he and his father were thrown out of their one-room apartment in Desowa because they could not pay the three thousand rida monthly rent demanded by his landlord.

Of relevance to this analysis is the register of violence or warfare, 'thrown', in the contact clause '(that) he and his father were thrown out of their one-room apartment in Desowa'. The clause is purposefully passive and agent-less to create temporary suspense and when the agent is included in the nonfinite clause that concludes the sentence, it is vague. The reader needs to read further so as to identify the referred landlord. This strategy is apt more so for an introductory chapter. More importantly, the predicator in 
the clause - thrown out, is synonymous with ejected and driven out. Semantically, throw out includes force and excludes fairness. The writer's choice of this phrasal verb out of such other tolerable options as: sent out, told to pack, and asked to move out is to foreground the wickedness of the rich. More glaringly, the conversation between Ahoka and his father on the reason the latter's employer, Okime, refuses to give him a gun despite his night security work presents the author's portrayal of the rich through Ahoka's fathers perspective:

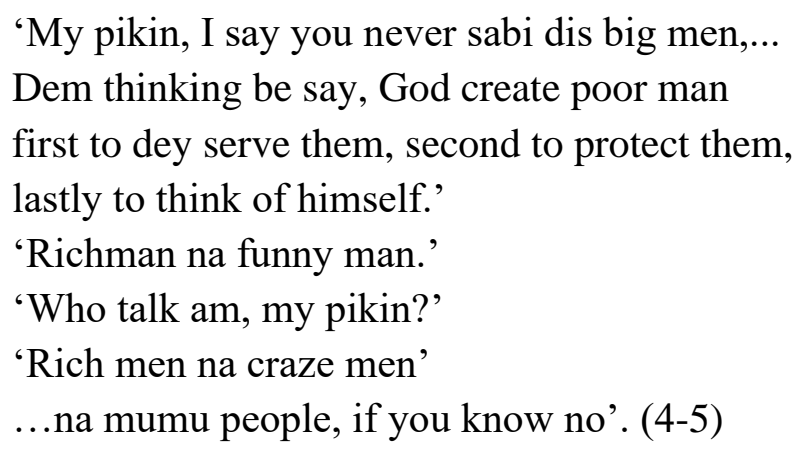

As shown by this except, Ahoka's father dominates the turns as a mark of superior knowledge and power. He predicates Ahoka's ignorance of the mentality of the rich with the negator 'never' included in the finite 'do not' and continues with his enlightenment mission. Ahoka's father here assigns to himself the role of a knower or sage. He further achieves this through his choice of the vocative 'my pikin' - a reminder of their tenor relationship and an endearment - and through self reporting clause - 'I say' - that amounts to emphatic assertion. Ahoka's father's analysis of the rich man's psyche is presented through enumerative conjuncts: 'first', 'second' and 'lastly'. The itemization is apt for his child co-interractant. Furthermore, the listing foregrounds the awkward pattern of thinking of the poor about the rich. The last of the trio of conjuncts underlines the unnaturalness of the principle of self last in matters of security and characterizes the rich as abnormal.

The deduction made by Ahoka from his father's psychoanalysis of the perception of the rich that ' rich man na funny man' disgusts his father leading to his subsequent descriptive explicitness through the process type chosen for him by the author. The two clauses: 'rich men na craze men' (rich men are crazy men) and 'na mumu people' (they are brainless people) are similarly construed in terms of the experience they relate to. In each case, the process type is relational of the intensive subtype. In other words, 'the rich men' or 'they' is the identified, while craze men or brainless people is the identifier. The relation of equation established between the rich and the mentally sick through the chosen process type reveals the brewing mutual hatred between the two divides and doubles as the author's device for suggesting to the reader the inevitability or at least the possibility of a clash between the two social groups in the course of the development of the plot of the story.

From the graphological angle of style, Usman's exploration of the hyphen is 
remarkable both in the introduction and throughout the novel. Each of the first four pages of the introduction features at least an instance of this morpho-graphological device as excerpted below:

'... he and his father were thrown out of their one-room apartment ...' (1)

' $\ldots$ the early morning rush to beat the nerve-breaking and patience-sapping Beku traffic'. (2)

'He heard of the dare-devilry with which the armed robbers in Beku operate with their self-loading rifles'. (3)

'So e get gun?' he asked, pausing his eating to stare open-mouthed at his father'. (4)

(Emphasis added)

The hyphen is employed morphologically to achieve compounding and it can be found between two or more words from the same or different word classes. It is employed contrariwise to separate a prefix ending in a vowel from a word that begins with the same vowel. Thus, the hyphen performs paradoxical functions of uniting and splitting and its extensive use in written discourse can be a clue to social unity and or separation. In the current novel, disunity is signaled by the hyphen and this becomes very deadly as the novel unveils.

In the first of the four excerpts, the descriptive term 'one-room' is preferred by the author over the more appropriate English option - bed sitting room. This choice is made up of the numeral adjective 'one' and the noun 'room' aligning with the morphology of such other words as: one-man, one- piece and one-parent. One-room is simplified in the manner of Nigerian English.

In the second excerpt, 'nerve-racking' and 'patience-sapping' are replaceable by the simple adjectives strenuous and frustrating respectively. But freshness and informality motivate the author's choice in each case. The two compound adjectives are composed of a verb and a participle making them phonological parallels. The writer's crave for musicality essential for the sustenance of the reader's interest is another stylistic motivation for this compounding.

Similarly, 'dare-devilry', the first of the two compound words in the penultimate excerpts above involves resonance orchestrated by the repetition of the alveolar plosive /d/. Unlike the earlier adjectives, this noun may not require a hyphen. The choice to hyphenate its two words is perhaps for consistency and emphasis. Also, the author's choice of 'dare-devilry' out of other paradigmatic alternatives such as: recklessness and heedlessness is a product of manipulative ingenuity. The prefix 'self- ' in 'self-loading', is synonymous to the ones in self-rising and self- regulating and it is the grammatical motivation for its formation. Contextually, 'self-loading' is a synonym for automatic. Besides being informal and therefore suitable for the narration, 'self-loading', sounds immediately more frightening than automatic.

In the last excerpt, 'open-mouthed' is an adverb coined by a replication of the morphological processes of such words as; open-hearted and open-handed. It means any 
of astonishingly, amazingly and agape. Again, 'open-mouthed' possesses extra-graphical modification accuracy. In all, the stylistic facility of compounding is deftly annexed by Usman to achieve peculiar communicative success, entertain the reader and display his literary dexterity.

\section{Conclusion}

The task of creating narrative is essentially that of writing and re-writing which is requisite for aptness. Revising or editing itself is a product of reconsideration of lexical, semantic, textual, and syntactic choices made. The final piece available for the reader's consumption is the refined one characterized by its attention retention capacity. Usman's Hope in Anarchy presupposes a failed optimism by the strange context it creates for hope through its inherently antithetical title. The contradiction is deftly introduced in the first chapter of the novel through different stylistic devices of contrast. Besides, the success of the novel stems from its morpho-phonological choices which underlie its novelty and literary typicality. These strategies are responsible for the interest and suspense created in the introduction and retained throughout the body of the story. Through the analysis provided in this work, the nexus between language and literature on the one hand and language and style on the other hand has been reinforced.

\section{Works Cited}

Abubakar, Rasheed. 'Systemic Perspective is Narrative.' New Approaches to Literary and Linguistic Analysis. LAN, 1997, pp. 1-23.

Halliday, M. A. K. An Introduction to Functional Grammar ( ${ }^{\text {rd }}$ Edition). Arnold, 2004.

Lawal, Adebayo. 'Semiotic Perspective on the Place of Linguistic Competence in a Theory of Literary Competence'. Stylistics in Theory and Practice. Paragon Books. 1997, pp. 2547.

Leech, G. N. and Short, M. H. Style in Fiction. Longman, 1981.

Moody, H. L. B. Literary Appreciation. Longman, 1968.

Olaofe, Isaac. O. and Kasim, Alti. Grammar and Usage for Writers of English. Yahaya Venture, 2013.

Oyeleye, Lekan. 'Aspects of the use of Language in African Poetry: Soyinka, Clark and Diop as case studies.' Literature, Ideology and Society: Essays in Honour of Abiola Irele. AMD Publishers, 1998, pp. $254-273$.

Quirk, Randolph, and Greenbaum, Sidney. University Grammar of English. Longman, 1973

Traugott, E. I. and Pratt, M. I. Linguistics for Students of Literature. Harcourt Brace Jovanovich. 1980.

Turner, G. W. Stylistics. Harmondsworth: Penguin Books, 1973.

Usman, Adamu Kyaku. Hope in Anarchy. UPL, 2007. 


\section{The Author}

\section{Muniru Murana Oladayo}

Department of European Languages, Federal University Birnin-Kebbi, Kebbi State, Nigeria

Email: muranamuniru1@gmail.com

\section{Hafsat AbdulWahab}

Department of English, Government Secondary School, Dakace, Zaria, Kaduna State, Nigeria

\section{Email: hafsymuran@gmail.com}

\section{The Article}

Date Sent: 09/12/2020

Date Revised: 21/01/2021

Date Accepted: 22/01/2021 